"This document is the Accepted Manuscript version of a Published Work that appeared in final form in the American Society copyright (C) American Chemical Society after peer review and technical editing by the publisher. To access the final edited and published work see [insert ACS Articles on Request authordirected link to Published Work, see http:// pubs.acs.org/doi/abs/10.1021/jacs.6b04088."

\title{
Ni-catalyzed Carboxylation of Unactivated Alkyl Chlorides with $\mathrm{CO}_{2}$
}

\author{
Marino Börjesson, ${ }^{\dagger}$ Toni Moragas ${ }^{\dagger}$ and Ruben Martin ${ }^{\dagger}{ }^{\dagger *}$
}

†Institute of Chemical Research of Catalonia (ICIQ), The Barcelona Institute of Science and Technology, Av. Països Catalans 16, 43007 Tarragona, Spain

$\S$ Catalan Institution for Research and Advanced Studies (ICREA), Passeig Lluïs Companys, 23, 08010, Barcelona, Spain

Supporting Information Placeholder

ABSTRACT: A catalytic carboxylation of unactivated primary, secondary \& tertiary alkyl chlorides with $\mathrm{CO}_{2}$ at atmospheric pressure is described. This protocol represents the first intermolecular cross-electrophile coupling of unactivated alkyl chlorides, thus leading to new knowledge in the cross-coupling arena.

Catalytic cross-electrophile coupling processes of organic (pseudo)halides have gained considerable momentum, ${ }^{1}$ representing straightforward alternatives to classical nucleophilic/electrophilic regimes based on welldefined, and in many instances, air-sensitive organometallic reagents (Scheme 1, path $\mathrm{b}$ vs path a). ${ }^{2}$ While notorious difficult transformations have been developed, the formidable high activation energy required for effecting $\mathrm{C}\left(\mathrm{sp}^{3}\right)-\mathrm{Cl}$ cleavage and the inherent proclivity of alkyl metal species towards parasitic $\beta$-hydride elimination or homodimerization pathways ${ }^{3}$ has contributed to the prevailing perception that unactivated alkyl chlorides cannot be utilized in intermolecular cross-electrophile events. ${ }^{4,5}$ If successful, however, such a largely void terrain would not only lead to new knowledge in retrosynthetic analysis, but also would set the stage for iterative techniques with polyhalogenated backbones, ${ }^{6}$ a highly rewarding scenario that would dramatically improve our ever-expanding synthetic portfolio.

\section{Scheme 1. Unactivated Alkyl Chlorides in Cross-Coupling.}

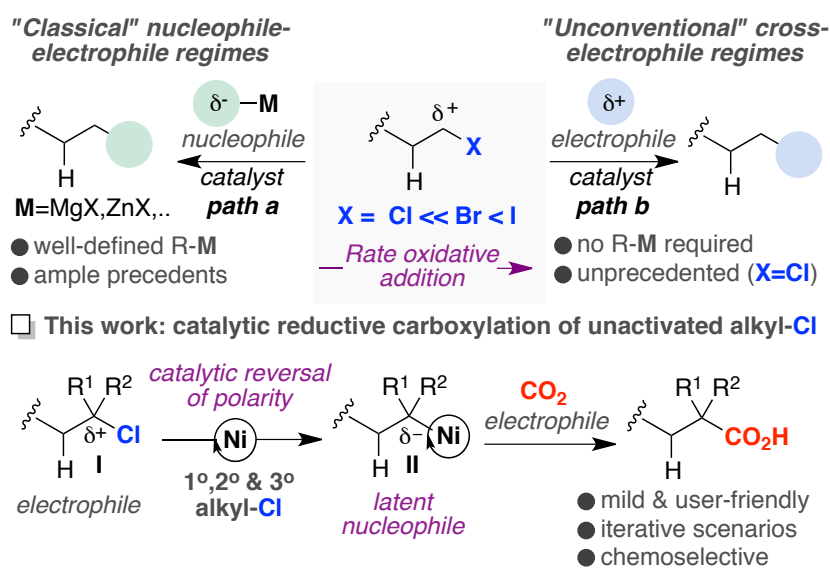

In recent years, carbon dioxide $\left(\mathrm{CO}_{2}\right)$ has gained considerable momentum as $\mathrm{C} 1$ synthon in catalytic endeavors, holding promise to create new paradigms in synthetic sequences. ${ }^{7}$ Among these, the ability to prepare carboxylic acids from $\mathrm{CO}_{2}$ is particularly appealing due to the ubiquity of these recurrent motifs in a myriad of biologically-relevant molecules. ${ }^{8}$ Prompted by the work of Osakada, ${ }^{9}$ we $^{10}$ and others ${ }^{11}$ have described catalytic carboxylation techniques of organic (pseudo)halides. Despite the advances realized, (a) the carboxylation of unactivated secondary or tertiary organic (pseudo)halides still constitutes a daunting, yet unsolved, challenge and (b) unactivated alkyl chlorides cannot be employed as coupling partners, neither in carboxylation events nor in intermolecular cross-electrophile coupling reactions. ${ }^{4}$ Herein, we describe the realization of all these challenges by designing a catalytic carboxylation that allows for the coupling of unactivated primary, secondary and even tertiary alkyl chlorides (Scheme 1, bottom). This protocol operates with an exquisite chemoselectivity profile at atmospheric pressure of $\mathrm{CO}_{2}$ while obviating the need for stoichiometric organometallic reagents.

Table 1. Optimization of the Reaction Conditions. ${ }^{a}$ 


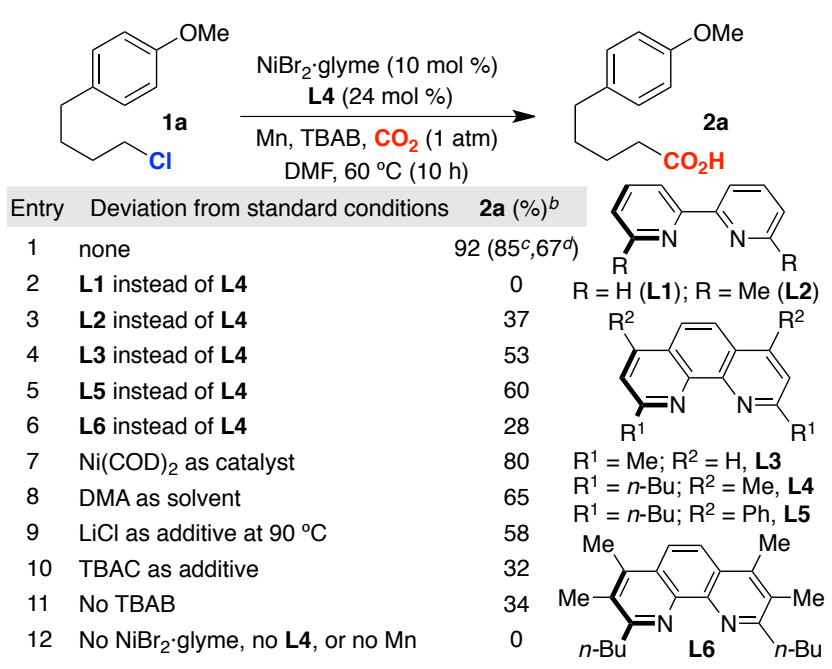

${ }^{a}$ 1a (0.20 mmol), $\mathrm{NiBr}_{2} \cdot$ glyme (10 mol\%), L4 (24 mol\%), Mn $(0.60 \mathrm{mmol})$, TBAB $(0.20 \mathrm{mmol})$ in $\operatorname{DMF}(0.16 \mathrm{M})$ at $60{ }^{\circ} \mathrm{C}$ under $\mathrm{CO}_{2}(1 \mathrm{~atm}) .{ }^{b} \mathrm{HPLC}$ yields using anisole as internal standard. ${ }^{c}$ Isolated yield. ${ }^{d} \mathrm{NiBr}_{2} \cdot$ glyme (5 mol\%).

Our study began by evaluating the reaction of UV-active $1 \mathbf{a}$ with $\mathrm{CO}_{2}(1 \mathrm{~atm})$. Traces of $\mathbf{2 a}$, if any, were detected under previously reported carboxylation events, ${ }^{10,11}$ reinforcing the notion that the carboxylation of 1 a would be far from trivial. After some experimentation, ${ }^{12}$ a combination of $\mathrm{NiBr}_{2} \cdot$ glyme, $\mathbf{L 4}, \mathrm{TBAB}, \mathrm{Mn}$ in DMF at $60{ }^{\circ} \mathrm{C}$ provided the best results, delivering $2 \mathrm{a}$ in $85 \%$ yield. ${ }^{13}$ As expected, the nature of the ligand backbone exerted a profound influence on the reaction outcome. Indeed, rigid phenanthroline backbones possessing orthosubstituents were particularly suited for our purposes, minimizing $\beta$-hydride elimination or homodimerization pathways (entries 4-6). As shown in entries 7 and 8, the use of other precatalyts or solvents had a deleterious effect. ${ }^{12}$ While one might argue that TBAB might be triggering a $\mathrm{Br} / \mathrm{Cl}$ exchange en route to alkyl-Ni(II)Br species,${ }^{14}$ the carboxylation with TBAC or LiCl suggests otherwise (entries $9-10) .^{15}$ Notably, $5-10 \%$ yield of $\mathbf{2 a}$ was obtained with $\mathbf{1 a}-\mathrm{Br}$ or $\mathbf{1 a}-\mathrm{I}$, resulting predominantly in $\beta$-hydride elimination or homodimerization. As expected, control experiments revealed that all variables were critical for success (entries 11-12). ${ }^{16}$

Table 2. Carboxylation of Unactivated Alkyl Chlorides. ${ }^{a, b}$

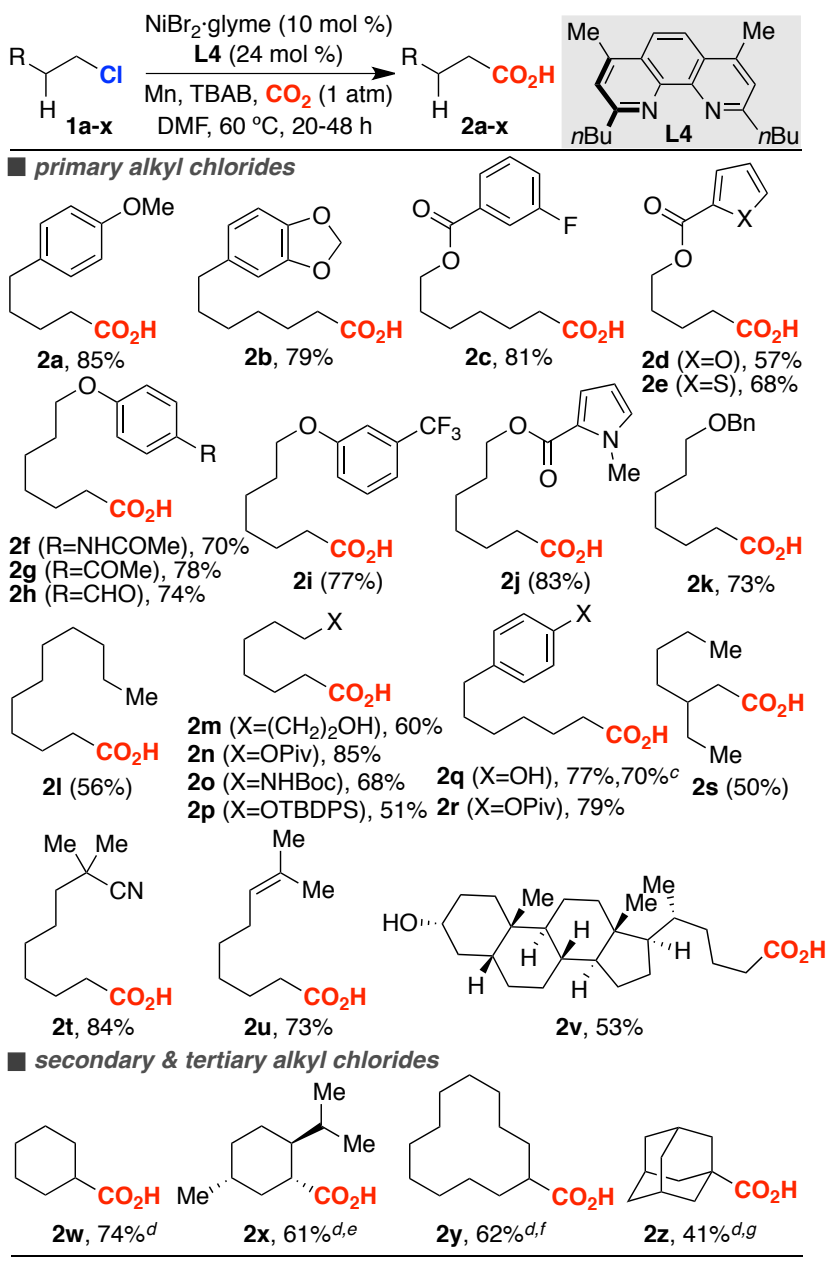

${ }^{a}$ As Table 1 , entry $1 .{ }^{b}$ Isolated yields, average of two independent runs. ${ }^{c} \mathbf{1 q}(1.5 \mathrm{mmol}) .{ }^{d} \mathrm{NiBr}_{2} \cdot \operatorname{diglyme}(10 \mathrm{~mol} \%)$, L6 $(24 \mathrm{~mol} \%), \mathrm{LiCl}$ (1 equiv), $90{ }^{\circ} \mathrm{C} .{ }^{e} 50^{\circ} \mathrm{C} .{ }^{f} 70{ }^{\circ} \mathrm{C} .{ }^{g} \mathrm{Us}-$ ing $\mathrm{Zn}$ ( 3 equiv) and TBAB ( 2 equiv) in DMA at $80^{\circ} \mathrm{C}$.

Encouraged by these results, we turned our attention to explore the generality of our protocol with a host of unactivated alkyl chlorides (Table 2). In line with our expectations, the reaction was rather general and distinguished by an exquisite chemoselectivity profile, as acetals $(\mathbf{2 b})$, esters $(\mathbf{2 c}, \mathbf{2 d}, \mathbf{2 e}$ and $\mathbf{2 j}$ ), aryl fluorides $(\mathbf{2 c})$, heterocycles (2d, $\mathbf{2 e}$ and $\mathbf{2} \mathbf{j}$ ), amides (2f), aldehydes $(\mathbf{2 h})$, ketones $(\mathbf{2 g})$, silyl ethers $(\mathbf{2 p})$, nitriles $(\mathbf{2 t})$, carbamates (2o) or alkenes (2u) could all be perfectly accommodated. Interestingly, free aliphatic alcohols $(\mathbf{2 m}$ and $2 \mathbf{v}$ ) or even their most acidic phenol congeners do not interfere (2q), thus illustrating the potential of our methodology in protecting-group-free strategies. While $\mathrm{C}-\mathrm{O}$ electrophiles have been utilized in Ni-catalyzed cross-coupling reactions, ${ }^{17,18}$ we found exclusive formation of $\mathbf{2 n}$ and $\mathbf{2 r}$, thus providing an additional handle for further functionalization. Although the available literature data suggested that the carboxylation of unactivated secondary or tertiary alkyl halides would be a chimera, we found that $\mathbf{2 w - 2 y}$ were within reach under a $\mathrm{Ni} / \mathbf{L 6}$ regime using $\mathrm{LiCl}$ as additive, even as single diastereoisomers as univocally shown by X-ray crystallog- 
raphy $(\mathbf{2} \mathbf{x})$. Albeit in lower yields, the preparation of $\mathbf{2} \mathbf{z}^{19}$ constitutes a rare example of a cross-electrophile coupling of unactivated tertiary alkyl halides ${ }^{20}$ showcasing the full potential of our catalytic protocol. With these conditions in hand, we wondered whether unactivated alkyl chlorides containing alkyne motifs on the side chain could trigger a $\mathrm{CO}_{2}$ insertion at distal reaction sites. As shown in Table 3, this was indeed the case, and carbocyclic skeletons possessing a carboxylic acid within a rather elusive tetrasubstituted olefin framework were all obtained in good yields (4a-4f) at $3 \mathrm{~mol} \%$ catalyst loadings, even at $3 \mathrm{mmol}$ scale (4c) using L5. Particularly noteworthy was the observation that a formal anti-carbometalation motion ${ }^{21}$ was favored when utilizing secondary alkyl chlorides based on a $\mathrm{Ni} / \mathbf{L} 6$ couple (4e and $4 f)^{22}$

Table 3. Cascade Cyclization/Carboxylation Events. ${ }^{a, b}$

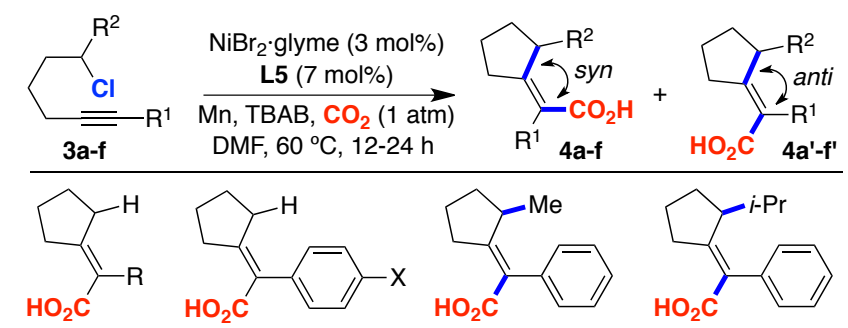

4a $(\mathrm{R}=\mathrm{H}), 46 \% \quad$ 4c $(X=\mathrm{H}), 77 \% c \quad 4 \mathrm{e}^{\prime}: 4 \mathrm{e}(3.6: 1), 59 \%{ }^{d} \quad \mathbf{4 f}^{\prime}: \mathbf{4 f}(7.1: 1), 42 \%{ }^{d}$ 4b (R=Me),55\% 4d (X=OMe),76\% 4e':4e (2.2:1),69\%e 4f':4f $(4.6: 1), 60 \%{ }^{e}$

${ }^{a}$ As Table 1 (entry 1), but using 3 mol\% loadings and L5. ${ }^{b}$ Isolated yields, average of at least two independent runs. ${ }^{c}$ 3c $(3 \mathrm{mmol}) .{ }^{d}$ Using $\mathbf{L 6}$ at $70{ }^{\circ} \mathrm{C} .{ }^{e} 90{ }^{\circ} \mathrm{C}$.

The feasibility of promoting an intermolecular crosselectrophile coupling reaction with unactivated alkyl chlorides suggested that our methodology could open up possibilities in iterative cross-coupling scenarios of polyhalogenated backbones. ${ }^{6}$ As illustrated in Scheme 2, 6 could be selectively prepared from densely halogenated 5 in a catalytic cross-electrophile coupling with tertbutyl bromide. ${ }^{20 a}$ Subsequently, Suzuki-Miyaura reaction using a Buchwald protocol under a $\mathrm{Pd} / \mathrm{XPhos}$ regime $^{23}$ resulted in 7 , which ultimately generated 8 upon simple exposure to our optimized carboxylation conditions based on L4. Taken together, the results of Tables 2-3 and Scheme 2 tacitly illustrates the prospective impact of this methodology in both cross-electrophile couplings and catalytic carboxylation processes.

\section{Scheme 2. Iterative Coupling with Polyhalogenated Motifs.}

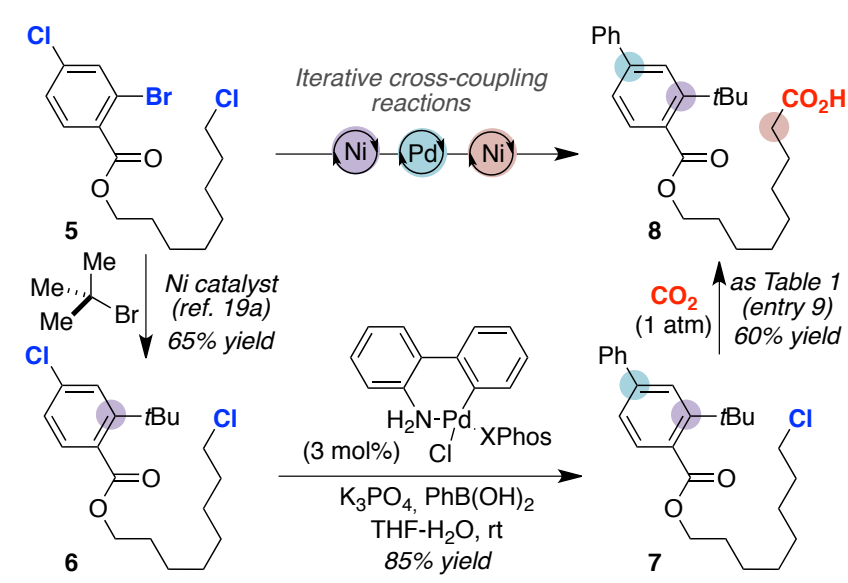

Next, we decided to gather indirect evidence about the mechanism by studying the stereochemical course of 9a and 9b (Scheme 3). As shown, an erosion of stereochemical integrity was observed regardless of the substrate utilized, suggesting that single-electron transfer processes (SET) and $\mathrm{Ni}(\mathrm{I})$ species might come into play. ${ }^{24,25}$ Taking this into consideration, we turned our attention to study the reactivity of the putative $\mathrm{Ni}(0)(\mathbf{L 4})_{2}$ (11) and $\mathrm{Ni}(\mathrm{I})(\mathbf{L} 4)_{2}$ (12) species, both of which could easily be prepared from $\mathrm{Ni}(\mathrm{COD})_{2} \cdot{ }^{10 \mathrm{a}}$ As expected, 11 was found to be catalytically competent as reaction intermediates, delivering $\mathbf{2 a}$ in $80 \%$ yield. Importantly, 2a was obtained in comparable yields when using stoichiometric amounts of $\mathbf{1 1}$ or $\mathbf{1 2}$, either in the absence or in the presence of TBAB, thus confirming that $\mathrm{TBAB}$ was not essential for the reaction to occur and leaving a reasonable doubt about the involvement of in situ generated alkyl-Ni(II)Br species. ${ }^{26}$, Athough we cannot rule out other conceivable pathways, ${ }^{27}$ at present we propose a catalytic scenario consisting of the initial formation of alkyl-Ni(II)Cl species followed by comproportionation with $\mathrm{Ni}(0) \mathrm{L}_{\mathrm{n}}$ en route to putative alkyl$\mathrm{Ni}(\mathrm{I})$ species ${ }^{28}$ that might rapidly insert $\mathrm{CO}_{2}$ into the $\mathrm{C}\left(\mathrm{sp}^{3}\right)-\mathrm{Ni}$ bond prior SET mediated by $\mathrm{Mn},{ }^{29}$ ultimately recovering back the propagating $\mathrm{Ni}(0) \mathrm{L}_{\mathrm{n}}$ species. ${ }^{30}$

\section{Scheme 3. Mechanistic Experiments.}


Stereochemical course of $\mathbf{9 a}$ and $\mathbf{9 b}$

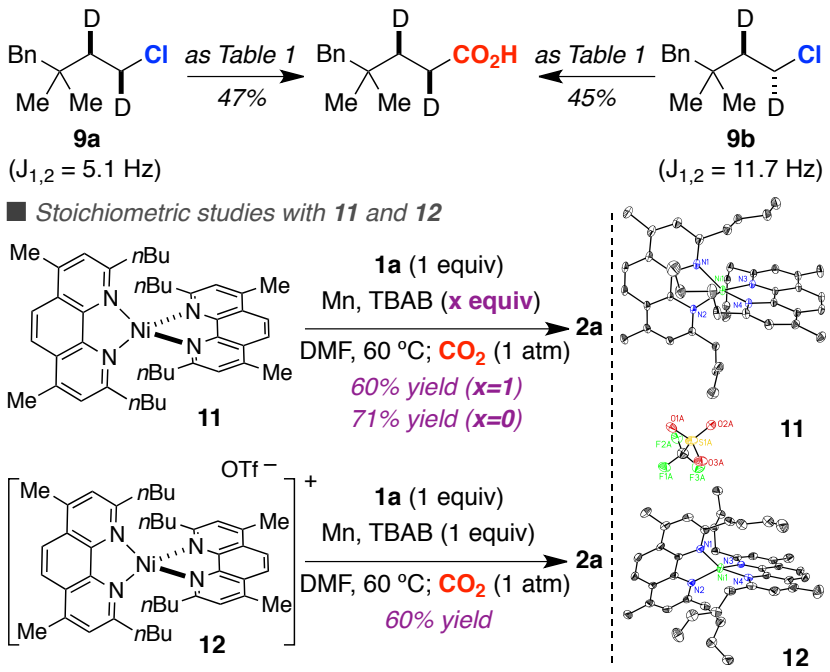

In summary, we have documented an unconventional intermolecular cross-electrophile coupling of unactivated primary, secondary or even tertiary alkyl chlorides with $\mathrm{CO}_{2}$ at atmospheric pressure. The salient features of this novel transformation are the exquisite chemoselectivity profile, mild conditions and ease of execution, allowing for cascade processes or iterative scenarios. Further extensions to other intermolecular crosselectrophile processes are currently underway.

\section{ASSOCIATED CONTENT}

Supporting Information. Experimental procedures and spectral data. This material is available free of charge via the Internet at http://pubs.acs.org.

\section{AUTHOR INFORMATION}

\section{Corresponding Author}

*rmartinromo@iciq.es

\section{Funding Sources}

No competing financial interests have been declared.

\section{ACKNOWLEDGMENT}

We thank ICIQ, the European Research Council (ERC277883), MINECO (CTQ2015-65496-R \& Severo Ochoa Excellence Accreditation 2014-2018, SEV-2013-0319) and Cellex Foundation for support. Johnson Matthey, Umicore and Nippon Chemical Industrial are acknowledged for a gift of metal \& ligand sources. M. B thank MINECO for a FPU fellowship. We sincerely thank E. Escudero and E. Martin for X-Ray crystallographic data.

\section{REFERENCES}

(1) For selected reviews: (a) Gu, J.; Wang, X.; Xue, W.; Gong, H. Org. Chem. Front. 2015, 3, 1411. (b) Weix, D. J. Acc. Chem. Res. 2015, 48, 1767. (c) Moragas, T.; Correa, A.; Martin, R. Chem. Eur. J. 2014, 20, 8242. (d) Knappke, C. E. I.; Grupe, S.; Gärtner, D.; Corpet, M.; Gosmini, C.; Jacobi von Wangelin, A. Chem. Eur. J. 2014, 20, 6828.
(2) (a) Tasker, S. Z.; Standley, E. A.; Jamison, T. F. Nature 2014, 509, 299. (b) Diederich, F.; Meijere, A., Eds. MetalCatalyzed Cross-Coupling Reactions; Wiley-VCH: Weinheim, 2004.

(3) For selected reviews dealing with unactivated alkyl halides, see: (a) Kambe, N.; Iwasaki, T.; Terao, J. Chem. Soc. Rev. 2011, 40, 4937. (b) Jana, R.; Pathak, T. P.; Sigman, M. S. Chem. Rev. 2011, 111, 1417.

(4) For a single example of a reductive homodimerization of an unactivated alkyl chlorides: Prinsell, M.; Everson, D.; Weix, D. J. Chem. Commun. 2010, 46, 5743. For a recent intramolecular ring-contraction: Tollefson, E. J.; Erickson, E. W.; Jarvo, E. R. J. Am. Chem. Soc. 2015, 137, 9760.

(5) Selected coupling of unactivated alkyl chlorides with nucleophile/electrophile regimes: (a) Atack, T. C.; Cook, S. P. J. Am. Chem. Soc. 2016, 138, 6139. (b) Lu, Z.; Fu, G. C. Angew. Chem., Int. Ed. 2010, 49, 6676, and references therein.

(6) For selected reviews: (a) Renzo, R.; Bellina, F.; Lessi, M. Tetrahedron 2011, 67, 6969. (b) Fairlamb, I. J. S. Chem. Soc. Rev. 2007, 36, 1036.

(7) (a) Zhang, L.; Hou, Z. Chem. Sci. 2013, 4, 3395; (b) Tsuji, Y.; Fujihara, T. Chem. Commun. 2012, 48, 9956. (c) Cokoja, M.; Bruckmeier, C.; Rieger, B.; Herrmann, W. A.; Kuhn, F. E. Angew. Chem., Int. Ed. 2011, 50, 8510. (d) Huang, K.; Sun, C. -L.; Shi, Z. -J. Chem. Soc. Rev. 2011, 40, 2435. (e) Martin, R.; Kleij, A. W. ChemSusChem 2011, 4, 1259.

(8) (a) Patai, S. The Chemistry of Acid Derivatives; Wiley: New York, 1992. (b) Goossen, L. J.; Rodríguez, N.; Goosen, K. Angew. Chem., Int. Ed. 2008, 47, 3100. (c) Maag, H. Prodrugs of Carboxylic Acids; Springer: New York, 2007.

(9) Osakada, K.; Sato, R.; Yamamoto, T. Organometallics 1994, 13, 4645.

(10) Selected references: (a) Moragas, T.; Gaydou, M.; Martin, R. Angew. Chem., Int. Ed. 2016, 55, 5053. (b) Wang, X.; Nakajima, M.; Martin, R. J. Am. Chem. Soc. 2015, 137, 8924. (c) Wang, X.; Liu, Y.; Martin, R. J. Am. Chem. Soc. 2015, 137, 6476. (d) Moragas, T.; Cornella, J.; Martin, R. J. Am. Chem. Soc. 2014, 136, 17702. (e) Liu, Y.; Cornella, J.; Martin, R. J. Am. Chem. Soc. 2014, 136, 11212.

(11) Selected references: (a) Rebih, F.; Andreini, M.; Moncomble, A.; Harrison-Marchand, A.; Maddaluno, J.; Durandetti, M. Chem. Eur. J. 2016, 22, 3758. (b) Nogi, K.; Fujihara, T.; Terao, J.; Tsuji, Y. J. Org. Chem. 2015, 80, 11618. (c) Mita, T.; Higuchi, Y.; Sato, Y. Chem. Eur. J. 2015, 21, 16391. (d) Nogi, K.; Fujihara, T.; Terao, J.; Tsuji, Y. Chem. Commun. 2014, 50, 13052. (e) Tran-Vu, H.; Daugulis, O. ACS Catal. 2013, 3, 2417. (f) Fujihara, T.; Nogi, K.; Xu, T.; Terao, J.; Tsuji, Y. J. Am. Chem. Soc. 2012, 134, 9106.

(12) See Supporting Information for details.

(13) Traces of $\beta$-hydride elimination were observed in the crude mixtures under our optimized reaction conditions.

(14) Under the limits of detection, no alkyl bromide was detected through the coufse of the reaction of 1a with TBAB by HPLC-monitoring in the absence or presence of $\mathrm{CO}_{2}$.

(15) Ammonium hat desahave been proposed to speed up electron-transfer processes $\mathrm{Mn}$ to the metal center: (a) Iyoda, At.; Otsal a, H.; Sato, K.; Nisato, N.; Oda, M. Bull. Chem. Soc. Ppne1990, 63, 80, and refs. 10d and 11f.

(16) The use of $\mathrm{Zn}$ as reductant with either $1 \mathbf{a}$ or $\mathbf{1 w}$ resulted in a significant erosion in yield ( $68 \%$ \& $30 \%$, respectively).

(17) (a) Tobisu, M.; Chatani, N. Acc. Chem. Res. 2015, 48, 1717. (b) Cornella, J.; Zarate, C.; Martin, R. Chem. Soc. Rev. 2014, 43, 8081. (c) Yamaguchi, J.; Muto, K.; Itami, K. Eur. J. Org. Chem. 2013, 19. (d) Rosen, B. M.; Quasdorf, K. W.; Wilson, D. A.; Zhang, N.; Resmerita, A. -M.; Garg, 
N. K.; Perce, V. Chem. Rev. 2011, 111, 1346. (e) Yu, D. G.; Li, B. -J.; Shi, Z. -J. Acc. Chem. Res. 2010, 43, 1486.

(18) $\mathrm{C}\left(\mathrm{sp}^{2}\right)-\mathrm{O}$ electrophiles have shown to be suited for catalytic reductive carboxylation techniques: Correa, A.; León, T.; Martin, R. J. Am. Chem. Soc. 2014, 136, 1062.

(19) Non-caged tertiary alkyl chlorides provided traces of carboxylation products.

(20) (a) Wang, X.; Wang, S.; Xue, W.; Gong, H. J. Am. Chem. Soc. 2015, 137, 11562. (b) Zhao, C.; Jia, X.; Wang, X.; Gong, H. J. Am. Chem. Soc. 2014, 136, 17645.

(21) The anti-motion is tentatively ascribed to the intermediacy of radical intermediates. See ref. 10c.

(22) For selected anti-carbometalation techniques of organometallic species, see: (a) Fressigne, C.; Girard, A. -L.; Durandetti, M.; Maddaluno, J. Angew. Chem. Int. Ed. 2008, 47, 891. (b) Simaan, S.; Marek, I. Org. Lett. 2007, 9, 2569, and references therein.

(23) Kinzel, T.; Zhang, Y.; Buchwald, S. L. J. Am. Chem. Soc. 2010, 132, 14073.

(24) In line with this notion, significant inhibition was observed with radical scavengers such as TEMPO or BHT. The presence of radical species gains credence by observing 5-exotrig cyclization at different $\mathrm{Ni} / \mathbf{L} \mathbf{4}$ loadings when employing 6-chloro-1-hexene as substrate, suggesting that a radicalescape rebound mechanism might be occurring.

(25) For Ni(I) species generated upon SET, see refs. 10a-e, 11f and the following references: a) Laskowski, C. A.; Bungum, D. J.; Baldwin, S. M.; Del Ciello, S. A.; Iluc, V. M.; Hillhouse, G. L. J. Am. Chem. Soc. 2013, 135, 18272; b)
Breitenfeld, J.; Ruiz, J.; Wodrich, M. D.; Hu, X. J. Am. Chem. Soc. 2013, 135, 12004; c) Biswas, S.; Weix, D. J. J. Am. Chem. Soc. 2013, 135, 16192, and references therein.

(26) Importantly, a stoichiometric reaction of $1 \mathrm{a}$ with $\mathbf{1 1}$ in the absence of $\mathrm{Mn}$ revealed that $\mathrm{CO}_{2}$ insertion into the $\mathrm{C}\left(\mathrm{sp}^{3}\right)$ $\mathrm{Ni}$ bond occurred. This observation is noteworthy, as all previous carboxylations of unactivated alkyl electrophiles required the presence of $\mathrm{Mn}$, even with stoichiometric amounts of Ni complexes (refs. 10c and 10e), arguably indicating that a different mechanism takes place with alkyl chloride counterparts. See ref. 12

(27) At present, direct $\mathrm{CO}_{2}$ insertion into the $\mathrm{C}\left(\mathrm{sp}^{3}\right)-\mathrm{Ni}(\mathrm{II}) \mathrm{Cl}$ bond or in situ formation of alkyl-Ni(I) species via SET mediated by Mn cannot be excluded.

(28) For selected comproportionation events en route to $\mathrm{Ni}(\mathrm{I})$ species, see: a) Cornella, J.; Gomez-Bengoa, E.; Martin, R. J. Am. Chem. Soc. 2013, 135, 1997. b) Velian, A.; Lin, S.; Miller, A. J. M.; Day, M. W.; Agapie, T. J. Am. Chem. Soc. 2010, 132, 6296. c) Phapale, V. B.; Bunuel, E.; GarcíaIglesias, M.; Cardenas, D. J. Angew. Chem., Int. Ed. 2007, 46, 8790. d) Jones, G. D.; Martin, J. L.; McFarland, C.; Allen, O. R.; Hall, R. E.; Haley, A. D.; Brandon, R. J.; Konovalova, T.; Desrochers, P. J.; Pulay, P.; Vicic, D. A. J. Am. Chem. Soc. 2006, 128, 13175.

(29) Recently, $\mathrm{Ni}(\mathrm{I})$ species have shown to rapidly react with $\mathrm{CO}_{2}$ : Menges, F. S.; Craig, S. M.; Tötsch, N.; Bloomfield, A.; Ghosh, S.; Krüger, H. -J.; Johnson, M. A. Angew. Chem., Int. Ed. 2016, 55, 1282.

(30) See ref. 12 for a proposed mechanistic rationale.

Ni-catalyzed carboxylation of unactivated alkyl chlorides with $\mathrm{CO}_{2}$
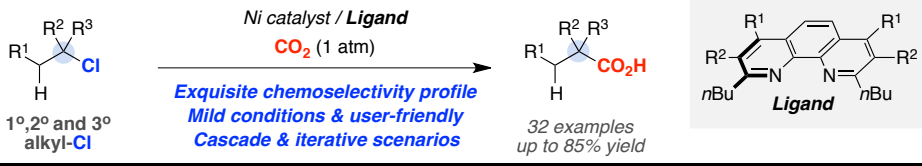